\title{
Involvement of Gynaecologists in Colorectal Cancer Screening
}

\author{
Norbert Kral ${ }^{1 *}$, Seifert Bohumil ${ }^{1}$, Suchanek Stepan ${ }^{2}$, Zavoral Miroslav ${ }^{2}$, Majek Ondrej ${ }^{3}$, Ngo Ondrej ${ }^{3}$ and Dusek Ladislav ${ }^{3}$ \\ ${ }^{1}$ Institute of General Practice, Charles University, Prague, Czech Republic \\ ${ }^{2}$ Department of Medicine, Central Military Hospital, Charles University, Prague, Czech Republic \\ 3 Institute of Biostatistics and Analyses, Masaryk University, Brno, Czech Republic
}

*Corresponding author: Norbert Kral, Institute of General Practice, Charles University, Prague, Czech Republic, Tel: +420723345931; E-mail: norbert.kral@seznam.cz Received date: May 09, 2017; Accepted date: May 10, 2017; Published date: May 15, 2017

Copyright: (c) $2017 \mathrm{Kral} \mathrm{N}$, et al. This is an openaccess article distributed under the terms of the Creative Commons Attribution License, which permits unrestricted use, distribution, and reproduction in any medium, provided the original author and source are credited

\begin{abstract}
Background and study aims: Primary care physicians play a principal role in colorectal cancer (CRC) screening in many countries that are using a two-step program; faecal occult blood test (FOBT)+colonoscopy. In order to improve the screening uptake in the Czech Republic ambulatory gynaecologists in addition to GPs were involved in FOB testing in 2009. Our objective was to describe the contribution of gynaecologists to the provision of CRC screening.
\end{abstract}

Methods: Data reported to health insurance companies and aggregated by the Czech National Reference Centre were used to monitor the screening process. We focused on the coverage by FOBT examination and positive FOBT rate. We describe time trends in the number and proportion of people tested, describe regional variations and show differences according to sex and age.

Results: The target population for CRC screening above age 50 in the Czech Republic was 3,955,968 (37.7\% of total population) in 2014. The number of all FOBT performed in primary care (by GPs and gynaecologists) increased from 357,893 in $2008(417,364-2009)$ to 744,015 in 2014 . In 2012, the total coverage of the target population was $25.5 \% ; 23 \%$ of men and $27.5 \%$ of all women and in $201430.8 \%, 28.5 \%$ of men and $32.8 \%$ of women. In the years $2009,2012,2014$ the total contribution of gynaecologists was $3.6 \%, 8 \%$ and $6.4 \%$ respectively, of all FOBT performed. Overall in the female target population it was $6.2 \%$ in 2009 (out of 236987 ) $13.6 \%$ in 2012 (out of 325,631 FOBT) and $11.2 \%$ in 2014 (out of 423660 ), while in the $50-54$ age group $24.4 \%$ women were screened by gynaecologists in 2012 and $18.9 \%$ in 2014 . The data showed significant variations between the 14 regions of the country. The overall positivity rate of FOBT has increased from $4.6 \%$ in 2009 to $7.2 \%$ in the year 2014 .

Conclusions: The participation of gynaecologists has contributed significantly to the higher participation of women in the real life Czech CRC screening program, particularly in the 50-54 years old age group, nevertheless the key responsibility stays with GPs. This measure is likely to be applicable in health care systems with a network of ambulatory gynaecologists, as is the case in the Czech Republic and in most Central and Eastern European countries.

Keywords: Primary care; Colorectal cancer; Gynaecologists; Health care

\section{Introduction}

Colorectal cancer (CRC) is the second most commonly diagnosed form of cancer in Europe, with over 400,000 cases diagnosed each year [1]. By 2020, the annual incidence is expected to rise to 502,000 cases [2]. The five-year relative survival rate following CRC diagnosis has been improving during the last decade due to advances in diagnosis and treatment [3]. There are over 3 million people living with CRC in Europe. CRC accounted for 212000 deaths in 2008 and this is expected to rise to 248,000 in 2020 [2,4-7].

There is good evidence of the benefits of screening through mortality reduction. CRC screening belongs, together with breast and cervical cancer screening, to the three screening program that fulfil WHO requirements and whose implementation has been recommended by the Council of the European Union [8]. European guidelines for quality assurance in CRC screening and diagnosis have been available since 2010 [9,10]. Nevertheless a number of countries in Europe have been introducing or piloting organized screening program with considerable variations $[11,12]$. The most common design of the program is based on faecal occult blood testing (FOBT) for men and women aged 50-74 years [10] annually or biennially, with varying involvement of primary care physicians. In some countries (Germany, Czech Republic, Slovakia, France) primary care physicians play a principal role in recruiting people, counselling screening, performing FOBT, dealing with negative or positive results and referring for a colonoscopy $[13,14]$. In other countries they just have an advisory role (UK, The Netherlands, and Slovenia). The differences reflect variations in health care structures and systems but also differing levels of knowledge and awareness, factors which are relevant to educational and research policy. So far, the implementation of CRC screening is suboptimal and many consider a greater role for primary care as a key to optimal efficiency of CRC screening [4,6,11,14-18]. The international exchange of information, sharing of knowledge, experience and awareness of pitfalls in screening is essential for the progress of screening and the fight against CRC [19]. 
Page 2 of 5

The Czech Republic (population 10.5 million) ranks high among European countries in CRC incidence (age standardized rate 57.9 per 100,$000 ; 5^{\text {th }}$ place) and mortality $\left(24.1\right.$ per 100,$000 ; 9^{\text {th }}$ place) $[20]$. The Czech Republic belongs among those countries with the longest tradition of screening-the program was introduced in 2000 as an organized two-step program; faecal occult blood test (FOBT) + colonoscopy [21].

The program included an asymptomatic population from the age of 50 without any upper age limit. The decision on the eligibility of individuals for screening was left to the general practitioner's discretion. Guaiac FOBTs were distributed, collected and analyzed in surgeries of general practitioners (GP). The reimbursement was provided when test was completed. Patients with positive results were referred to gastroenterological outpatient or inpatient clinics. The screening program has been driven by The National Board for CRC screening [22].

Despite 12-years of the existing program in the Czech Republic, coverage was unsatisfactory and did not exceed $20 \%$ of the target population. In order to improve participation in screening, several changes were introduced in 2009:

1. FOBT performed on an annual basis at 50-54 years of age, then biennially after 55 . Immunochemical tests (both qualitative and quantitative, no cut-off centrally recommended) were approved for screening.

2. Not just GPs but also primary care gynaecologists were involved in FOBT screening.

3. The option of a primary screening colonoscopy at the age of 55 and at 10 -year screening intervals was introduced. A network of centers for screening colonoscopy was established.

The concept of the family doctor is not applied in primary care in the Czech Republic. Beside general practitioners (5290 physicians) and paediatricians (2075 physicians), gynaecologists (1300 physicians) serve in primary care as first line practitioners [23]. Primary care gynaecologists play an important role in screening for breast cancer and a principal role in cervical cancer screening. This unique experience and position in screening programs was taken into consideration by The National Board for CRC screening in making the decision about the involvement of gynaecologists. Gynaecologists have been provided with the same reimbursement for the immunochemical test completed.

Our objective was to describe the contribution of gynaecologists to the provision of CRC screening with FOBT and discuss how screening coverage has improved for different subgroups of the Czech population.

\section{Methods}

There is a centralized system of data monitoring established for all three organized screening program in the Czech Republic. The results are available for The National Board for CRC screening and are used for information, education and assessment of providers from different disciplines, at different levels and locations.

Both screening tests and subsequent examinations in the Czech Republic have their costs reimbursed from the public health insurance with practically universal population coverage; therefore, data on medical procedures reported to health insurance companies can be used to support the monitoring process. The Czech National Reference Centre has played a key role in the aggregation of this data from all health insurance companies. Data analysis itself has been performed by the Institute of Biostatistics and Analyses at Masaryk University.

In our analysis, we focused on key performance indicators proposed by the European Guidelines [9], the coverage by examination (FOBT), computed as a ratio of the number of people tested within the screening intervals ( 1 or 2 years) to the number of people in the target population at the end of the reporting period, and the positive FOBT rate. We describe time trends in the number and proportion of people tested and show differences according to sex and age. We discuss the involvement of gynaecologists in providing the FOBT screening and also describe regional variations, which were analyzed at the level of regions (population of 0.5-1.0 million) or districts (population of 50 thousands-0.5 million).

\section{Results}

The target population for CRC screening above age 50 in the Czech Republic was 3,867,965 (36.6\% of total population) in 2012 and $3,955,968$ (37.7\% of total population) in 2014 . The number of all FOBT performed in primary care (by GPs and gynaecologists) increased from 357,893 in 2008 to 419,917 in 2009 , to 528,476 in $2010,553,141$ in 2011, 553,141 in 2012, 574108 in 2013 and 744,015 in 2014. This represents a significant increase since 2008 (Figure 1).

The total number of colonoscopies was 204,576 in 2009 contra 225,747 in 2012 and 263,060 in 2014. 3,389 in 2009 contra, 15,833 in 2012 and 23,365 in 2014 of them were reported as colonoscopies following a positive FOBT. In addition 981 in 2009 contra 4283 in 2012 and 9236 in 2014 screening colonoscopies were performed. 36,021 polypectomies were performed in $2009,45,820$ in 2012 and 59,551 in 2014. In 2012, the total coverage of the target population was $25.5 \%$; $23 \%$ of men and $27.5 \%$ of all women and in $201430.8 \%, 28.5 \%$ of men and $32.8 \%$ of women. Coverage of the target population $(3,955,968)$ by FOBT screening by sex and age, 2013-2014 (Figure 2).

In the years 2009, 2012 and 2014 the total contribution of gynaecologists was $3.6 \%, 8 \%$ and 6.3 respectively, of all FOBT performed. Overall in the female target population it was $6.2 \%$ in 2009 (out of 236987) 13.6\% in 2012 (out of 325,631 FOBT) and $11.2 \%$ in 2014 (out of 423660) (Figure 3). The coverage is higher among women in the younger age groups. The contribution of gynaecologists was different in different age groups. In the age group $50-54$ years $24.4 \%$ in 2012 and $18.9 \%$ in 2014 and consequently less for the older women. For women older than 75 years GPs predominated, performing over $95 \%$ of FOBT (Figure 4 ).
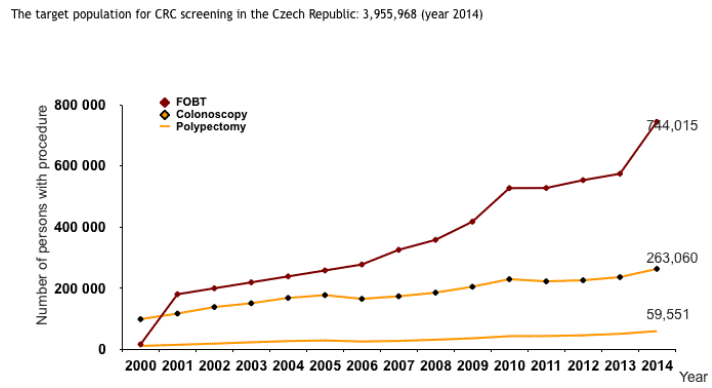

Figure 1: Time trends in number of patients undergoing medical procedures. Source of data: National Reference Centre. 


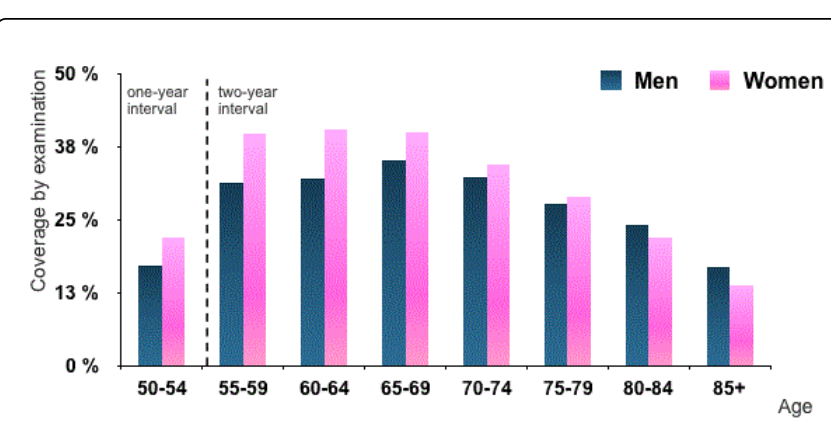

Figure 2: Coverage of target population $(3,955,968)$ by FOBT screening by sex and age, 2013-2014. Source of data: National Reference Centre.

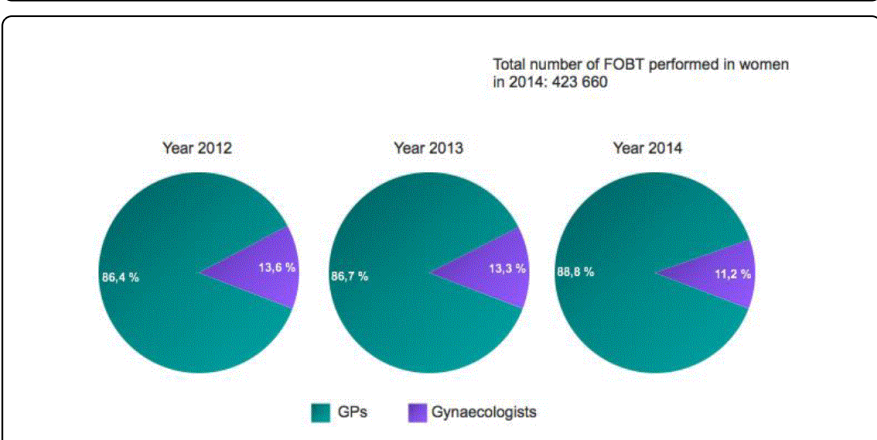

Figure 3: Proportion of FOBT in women by age performed by GPs or gynaecologists, 2012-2014. Source of data: National Reference Centre.

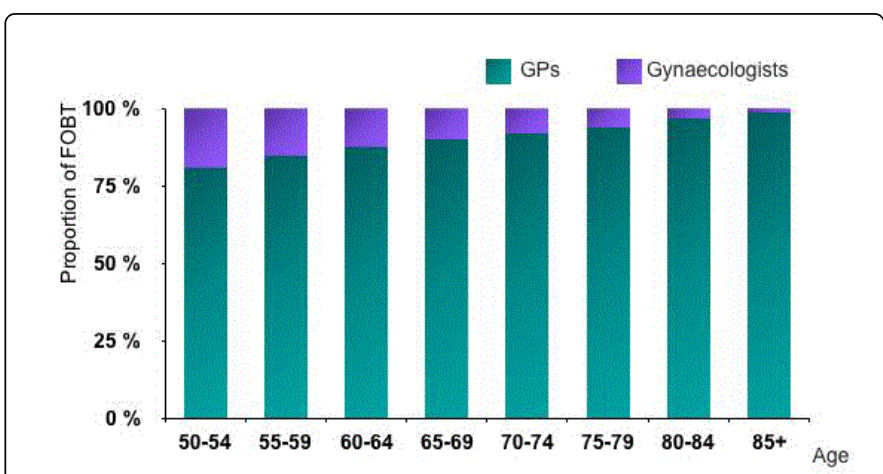

Figure 4: Proportion of FOBT in women by age performed by GPs or gynaecologists, 2013-2014. Source of data: National Reference Centre.

The data showed significant variations between the 14 regions of the country either in the total coverage or in the involvement of different primary care providers. The total coverage in 2013-2014 (30.8\%) varied from $23.9 \%$ to $40.0 \%$. While the proportion of FOBT performed by gynaecologists was $11.3 \%$ at the national level in the period 2013-2014, it was in the region from $5.4 \%$ to $18.1 \%$. The proportion of FOBT performed by gynaecologists among women is declining when compared to the years 2011 and 2014. In 56.25\% of districts of Czech Republic is a decrease, in the proportion of gynaecologists, stagnation is in a $27.5 \%$ of districts and increase only in $16.25 \%$ of districts.
Gynaecologists contribute significantly higher in regions with higher screening coverage. The overall positivity rate of FOBT has increased after introduction of immunochemical FOBT by up to $7.2 \%$ in 2014 . The FOBT positivity rate increases with age $(5.7 \%$ in individuals aged $50-54 ; 7.3 \%$ in those aged 70-74) and is slightly higher in men $(7.7 \%$ vs. $6.0 \%$ in women). Also the FOBT positivity rate varies from $5.9 \%$ to $8.6 \%$ at regional level (Figure 5).

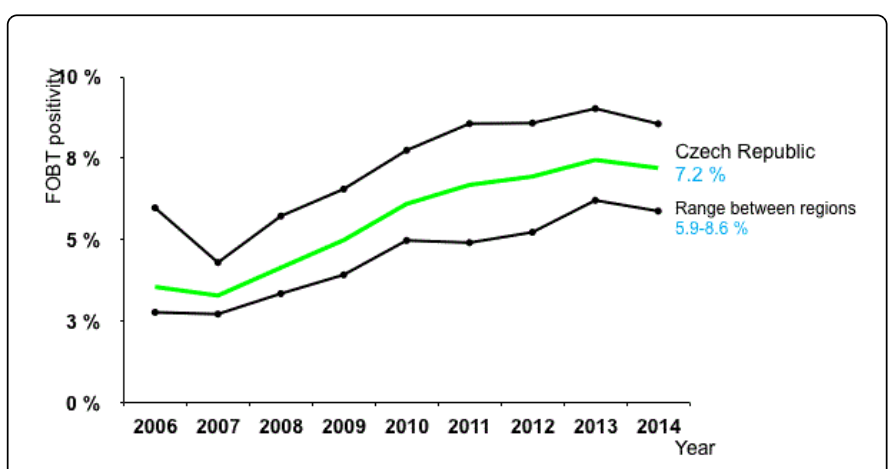

Figure 5: Time trend in FOBT possibility. Source of data: National Reference Centre.

The overall FOBT positivity rate in women increased from $4.6 \%$ in 2009 to $6.0 \%$ in 2011 . The positivity rate of FOBT performed by gynaecologists is higher $(7.8 \%$ in the year 2014$)$ than by general practitioners (5.9\% in 2014), and the variability among regions by gynaecologists is higher.

\section{Discussion}

The participation of gynaecologists has contributed to the higher participation of women, particularly in the 50-54 age groups. This is an age group of women with a higher adherence to gynaecologists than to GPs. These women mostly have husbands in the screening age and have the potential to influence them. The data also suggest there is a wide regional variation in the involvement of gynaecologists. Gynaecologists in approximately $25 \%$ of districts of the country did not participate in screening at all or did not contribute significantly (fewer than $5 \%$ of FOBT performed by gynaecologists). These findings are similar to the findings for GPs and reflect not only variations in the attitude to screening but also differing levels of knowledge and awareness. There is a potential for improvement through education, feedback of information and use of motivational tools including higher reimbursement [24]. The idea of involving gynaecologists in real life screening has its origin in consideration of their role and experience in the other two screening program and in the fact that women are more positive about screening and are capable of influencing their male partners, who are often reluctant to undergo a screening examination. Women under the age of 70 years old had a higher participation in FOBT screening than men $[6,7,18,22,25,26]$. Studies show that a second doctor's opinion and repetition of the information can increase compliance $[18,27,28]$. In addition women often limit their medical contacts only to visits to gynaecologists [29]. Studies exploring compliance among women who were offered the opportunity by gynaecologists of participating in all three screening modalities, showed a high compliance rate for breast and cervical cancer screening (93\% and $86 \%$ resp.) while only $66 \%$ complied with CRC screening [12]. 
Page 4 of 5

The involvement of gynaecologists in the CRC screening and representative nation-wide monitoring of their results is rather novel approaches which have only a few comparable references in the scientific literature. The extension of the screening to include gynaecologists and even urologists is the main concern of some German studies [30,31]. Stock et al. [31] from Germany have shown that gynaecologists play an important role in the provision of CRC screening by performing a large proportion of the patient education and almost all screening FOBTs for women. In the US, the recommendation of the American Society for Gynaecology and Obstetrics from 2011 suggests involving gynaecologists in CRC screening [32-35]. There are also studies exploring the possibility of a flexible sigmoidoscopy provided by gynaecologists [36]. With regard to the results of German studies [31], which have demonstrated a good of awareness on the part of GPs, gynaecologists and urologists of CRC screening, we can speculate whether, due to the lower participation of men compared to the adherence in women brought about by the involvement of gynaecologists in screening, the participation of urologists in screening for colorectal cancer should not be considered as well. The introduction of gynaecologists in CRC screening in the Czech Republic was initially controversial and accompanied by concern among GPs. GPs were rather sceptic and against the involvement of gynaecologists in CRC screening. GPs have a principal role in CRC screening and in prevention in general and the inclusion of other providers could weaken their position. For the patient the opinion of his GP is the strongest factor in deciding whether or not to take the test [14]. The other factor is fear [18]. There were also worries caused by doubts about the comparative performance of gynaecologists and GPs. None of these concerns were justified and after three years there were no more controversies.

Gynaecologists have shown adherence to guidelines not only in FOB testing but also in referring FOBT positive persons for colonoscopy and reporting. The most likely reason for the increased FOBT positivity rate is the ultimate use of qualitative immunochemical tests among gynaecologists whereas a substantial proportion of GPs still used guaiac FOBT in 2009-2010. Most gynaecologists perform the test on analyzer qualitative devices with a cut-off value of $100 \mathrm{ng} / \mathrm{ml}$. The increased FOBT positivity rate may also reflect a lower level of experience among gynaecologists in FOBT management. Similarly the FOBT positivity rate in general practice started at $6 \%$ and above in 2000 , when the program was introduced. The results of a study from the US suggest that gynaecologists and nurses did not differentiate appropriately between eligible and non-eligible (risk) patients [27,37]. The National Board for CRC screening has banned the use of guaiac tests since the beginning of 2013 and discussed the standardization of immunochemical tests. The key change has been implemented in the beginning of 2014: an addressed invitation system, changing an externally organized program to a population based one. The letter invites either to GP or gynaecologists. The introduction of a quantitative test with a cut-off level appropriate to local conditions will be the next step. The FOB quantitative point of care testing (POCT) systems as well as central analyzers is currently available in the Czech Republic.

\section{Strengths and Limitations}

The article presents balanced data from the real-life national program of colorectal cancer screening. The data system has practically universal coverage and includes all providers in all regions. The motivation of providers to deliver true data is ensured by the link to the reimbursement scheme. The data collection, analysis and presentation represent a feedback for the entire program. We are limited in our ability to compare the efficiency of involvement of gynaecologists in FOBT screening elsewhere because the research in this field is scarce. The limitations in our knowledge about the type of FOBT used in practice do not allow us to explain clearly the reasons for the higher FOBT positivity rate. We have also not yet been able to explain the variations between regions and districts.

\section{Conclusion}

The introduction of immunochemical tests, annual testing in the age group 50-54 years and the involvement of gynaecologists were observed to be effective measures for increasing screening coverage, while the introduction of primary screening colonoscopy did not substantially affect the uptake in screening. Our study shows that the involvement of primary care gynaecologists in FOB testing does increase the participation rate in colorectal cancer screening to some extent, nevertheless the key responsibility stays with GPs. The measure is likely to be applicable in health care systems with a network of ambulatory gynaecologists, as is the case not just in the Czech Republic and in most Central and Eastern European countries, but also in North America, as already mentioned.

\section{Acknowledgements}

Provision of data by National Reference Centre and support of National action plan for screening is gratefully acknowledged.

\section{References}

1. OECD (2012) Health at a Glance: Europe. OECD Publishing.

2. Ferlay J, Shin HR, Bray F, Forman D, Mathers C et al, Globocan 2008, Cancer Incidence and Mortality Worldwide: IARC CancerBase No. 10. Lyon: International Agency for Research on Cancer; 2010.

3. Pavlík T, Májek O, Büchler T, Vyzula R, Petera J, et al. (2014) Trends in stage-specific population-based survival of cancer patients in the Czech Republic in the period 2000-2008. Cancer Epidemiol 38: 28-34.

4. Kanavos P, Schurer W, Owusuapenten C, Sullivan R (2008) Colorectal cancer in Europe and Australia: Challenges and opportunities for the future. LSE Health, London School of Economics and Political Science, London, UK.

5. Ferlay J, Autier P, Boniol M, Heanue M, Colombet M, et al. (2007) Estimates of the cancer incidence and mortality in Europe in 2006. Ann Oncol 18: 581-592.

6. Zavoral M, Suchanek S, Zavada F, Dusek L, Muzik J, et al. (2009) Colorectal cancer screening in Europe. World J Gastroenterol 15: 5907-5915.

7. Dusek L (2012) Epidemiology, prevention a treatment of Colorectal cancer based on available studies and data. University Hospital Motol, Prague, pp: 204.

8. European Council (2003) Council Recommendation of 2 December 2003 on cancer screening. J Eur Union: OJ L327-L338.

9. Segnan N, Patnick J, von Karssa L (2010) European guidelines for quality assurance in colorectal cancer screening and diagnosis. (1st edn), J Eur Union.

10. European Colorectal Cancer Screening Guidelines Working Group (2013) European guidelines for quality assurance in colorectal cancer screening and diagnosis: Overview and introduction to the full supplement publication. Endoscopy 45: 51-59.

11. Denters MJ, Deutekom M, Fockens P, Bossuyt PM, Dekker E (2009) Implementation of population screening for colorectal cancer by repeated fecal occult blood test in the Netherlands. BMC Gastroenterol 9: 28. 
Citation: Kral N, Bohumil S, Stepan S, Miroslav Z, Ondrej M, et al. (2017) Involvement of Gynaecologists in Colorectal Cancer Screening . J Gen

Page 5 of 5

12. Weller D, Coleman D, Robertson R, Butler P, Melia J, et al. (2007) The UK colorectal cancer screening pilot: results of the second round of screening in England. Br J Cancer. 97: 1601-1605.

13. Král N, Seifert B (2010) Changes in screening for colorectal cancer - a step in the right direction? Oncology 4: 251-255

14. Viguier, J, Calazel-Benque A, Eisinger F, Pivot X (2011) Organized colorectal cancer screening programmes: How to optimize efficiency among general practitioners. Eur J Cancer Prev 20: 26-32.

15. Ginsberg GM, Lim SS, Lauer JA, Johns BP, Sepulveda CR et al. (2010) Prevention, screening and treatment of colorectal cancer: A global and regional generalized cost effectiveness analysis. Cost Eff Resour Alloc 18: 2.

16. Telford J, Levy AR, Sambrook JC, Zou D, Enns RA (2010) The costeffectiveness of screening for colorectal cancer, CMAJ 182: 1307-1313.

17. Berchi C, Guittet L, Bouvier V, Launoy G (2010) Cost-effectiveness analysis of the optimal threshold of an automated immunochemical test for colorectal cancer screening: Performances of immunochemical colorectal cancer screening. Int J Technol Assess Health Care 26: 48-53.

18. Májek O, Danes J, Zavoral M, Dvorák V, Suchánek S, et al. (2010) Czech national cancer screening programmes in 2010. Klin Onkol 23: 343-353.

19. Bretthauer M, Kalager M (2013) Principles, effectiveness and caveats in screening for cancer. Br J Surg 100: 55-65.

20. Ferlay J, Steliarova-Foucher E, Lortet-Tieulent J, Rosso S, Coebergh JWW, et al. (2013) Cancer incidence and mortality patterns in Europe: Estimates for 40 countries in 2012. Eur J Cancer 49: 1374-1403.

21. Zavoral M, Fric P, Suchánek S, Dusek L, Seifert B (2013) National screening program in sporadic colorectal carcinoma (KR-CA): Development, present, perspective. Onconet 1:16-19.

22. Seifert B, Zavoral M, Fric P, Bencko V (2008) The role of primary care in colorectal cancer screening: experience from the Czech Republic. Neoplasma 55: 74-80.

23. (2013) Activity of health establishments in selected branches of curative and preventive care. Czech Health Statistics Yearbook. UZIS CR.

24. Ziegler M, Krause S, Kolligs FT (2011) How physicians inform about colorectal cancer and screening, Z Gastroenterol 49: 584-590.

25. Sieverding M, Matterne U, Ciccarelo L (2008) Gender Differences in FOBT use: Evidence from a large German survey. Z Gastroenterol 46: 47-51.

26. Stock C, Brener H (2010) Utilization of lower gastrointestinal endoscopy and fecal occult blood test in 11 European countries: Evidence from the
Survey of Health, Aging and Retirement in Europe (SHARE). Endoscopy 42: 546-556.

27. Lieberman DA, Harford WV, Ahnen DJ (2001) One-time screening for colorectal cancer with combined fecal occult-blood testing and examination of the distal colon. N Engl J Med 345: 555-560.

28. Detsky AS (2001) Screening for colon cancer: Can we afford colonoscopy? N Engl J, Med 345: 607-608.

29. Giovannucci E, Rimm EB, Ascherio A (1995) Alcohol, low-methionine/ low-folate diets, and risk of colon cancer in men. J Natl Cancer Inst 87: 265-273.

30. Zauber AG, Lansdorp-Vogelaar I, Knudsen AB, Wilschut J, van Ballegooijen M, et al. (2009) Evaluating test strategies for colorectal cancer screening - age to begin, age to stop, and timing of screening intervals: A decision analysis of colorectal cancer screening for the U.S. preventive services task force from the Cancer Intervention and Surveillance Modeling Network (CISNET). Rockville (MD): Agency for Healthcare Research and Quality (US), Report No.: 08-05124-EF-2.

31. Stock C, Ihle P, Schubert I, Brenner H (2011) Colonoscopy and fecal occult blood test use in Germany: Results from a large insurance-based cohort. Endoscopy 43: 771-779.

32. Colonoscopy and colorectal cancer screening strategies. Committee Opinion No 482 (2011) Obstet Gynecol 117: 766-771.

33. Seltzer V (2002) Role of the obstetrician-gynecologist in reducing the incidence of and death rate from colorectal cancer. Clin Obstet Gynecol 245: 812-819.

34. Menees SB, Patel DA, Dalton V (2009) Colorectal cancer screening practices among obstetrician/gynecologists and nurse practitioners. J Women's Health (Larchmt) 18: 1233-1238.

35. Menees SB, Inadomi J, Elta G, Korsnes S, Punch M, et al. (2010) Colorectal Cancer Screening Compliance and Contemplation in Gynecology Patients. J Womens Health 19: 911-917

36. Ventura-Braswell AM, Brittain PC (1999) Sigmoidoscopic screening for colorectal neoplasia: A comparison of residents in obstetrics and gynecology to those in internal medicine in a military medical center. Prim Care Update Ob/Gyns 6: 177-180.

37. Rex DK, Bond JH, Winawer S (2002) Quality in the technical performance of colonoscopy and the continuous quality improvement process for colonoscopy: Recommendations of the U.S. Multi-Society Task Force on Colorectal Cancer. Am J Gastroenterol 97: 1296-1308. 